\title{
Effect of Aging on the Microhardness of Different Resin-based Fluoride-releasing Fissure Sealants: An In Vitro Study
}

\author{
Ayman M Sulimany ${ }^{1}$, Saad S BinSaleh ${ }^{2}$, Eram AlYahya ${ }^{3}$, Rawan Bataweel ${ }^{4}$, Imtinan Alhussain ${ }^{5}$, Ahmed Almahdy ${ }^{6}$
}

\begin{abstract}
Aim: The aim of the present study was to evaluate the effect of aging on the microhardness score [Vickers hardness number (VHN)] of different resin-based fluoride-releasing sealants compared to non-fluoride resin-based sealants.

Materials and methods: A total of 48 extracted sound molars that were sectioned mesiodistally were used. In the current study, four types of sealants were compared: Group A, a resin-based non-fluoride-releasing pit and fissure sealant (Eco-S sealant) served as a control. Groups B, C, and $D$ received resin-based fluoride-releasing pit and fissure sealants Helioseal F, Fissurit F, and Embrace ${ }^{\mathrm{TM}}$ WetBond, respectively. Subsequently, each group was further divided into immediate and aged subgroups. The samples had been evaluated regarding their microhardness using a pyramidal diamond indenter of a Vickers hardness test at two-time intervals: Immediately and after the aging process through thermocycling. Results: There were no statistically significant differences between mean VHN and material types $(p=0.72)$. Aging appeared to significantly increase the mean VHN $(p=0.001)$. The interaction model between material type and time factor showed that the effect of aging differs by the material type, where the VHN of the Embrace ${ }^{\mathrm{TM}}$ group increased significantly after aging from $24.33 \pm 5.60$ to $31.70 \pm 3.59(p=0.001)$.

Conclusion: While there were no significant differences in the microhardness of commonly used fluoride-releasing fissure sealants, time appears to significantly increase the mean microhardness score (VHN), especially in the Embrace ${ }^{\mathrm{TM}}$ group.

Clinical significance: Embrace ${ }^{\mathrm{TM}}$ WetBond fissure sealant showed a significant improvement in the mean microhardness score (VHN) with time. However, clinical studies with long-term follow-up are needed to confirm our results.

Keywords: Aging, Fissure sealant, Microhardness, Resin-based fluoride-releasing sealants.

The Journal of Contemporary Dental Practice (2021): 10.5005/jp-journals-10024-3153
\end{abstract}

\section{INTRODUCTION}

Dental caries remain a major global public health concerns ${ }^{1}$ with harmful consequences if left untreated, especially in the pediatric population. ${ }^{2,3}$ Most dental caries in children older than 6 years of age are confined to plaque retentive occlusal surfaces of first, followed by second, permanent molars. ${ }^{4,5}$ The introduction of fissure sealants more than half a century ago to prevent caries in pits and fissures of occlusal surfaces is now considered one of the most effective measures for managing initial caries lesions, especially in high-risk children. ${ }^{6}$

A large body of clinical evidence attests to the effectiveness of fissure sealants in preventing caries, ${ }^{7,8}$ especially during the eruption of the first permanent molars ${ }^{9}$ and primary molars. ${ }^{10}$ Furthermore, fissure sealants have been shown to arrest non-cavitated (incipient enamel) lesions on occlusal surfaces of molars. 6,11

The most common sealants include glass ionomers and composite-based sealants. ${ }^{12}$ Recent technological advances in the development of filled and unfilled resin materials with the addition of bioactive fluoride have further expanded the range of application selection of fissure sealant materials. In addition, resin-based sealants offer higher mechanical properties, including retention, fracture, and wear resistance, compared to other types of fissure sealants, ${ }^{13}$ and are, therefore, considered as the gold standard preventive measure by the American Dental Association. ${ }^{14}$ The clinical success and durability of fissure sealants depend on several factors, including chemical composition, physical and mechanical properties, and the oral environment. In recent years, fillers have improved the mechanical properties, especially wear resistance and hardness of fissure sealants, to withstand the occlusal forces, thermal, and $\mathrm{pH}$ changes in the oral environment. ${ }^{15}$ The content and

\footnotetext{
1,2,6 Department of Pediatric Dentistry and Orthodontics, College of Dentistry, King Saud University, Riyadh, Saudi Arabia

${ }^{3}$ Prince Sultan Military Medical City, Riyadh, Saudi Arabia

4,5 King Saud University, Riyadh, Saudi Arabia
}

Corresponding Author: Ayman M Sulimany, Department of Pediatric Dentistry and Orthodontics, College of Dentistry, King Saud University, Riyadh, Saudi Arabia, Phone: +966 506695718 e-mail: asulimany@ ksu.edu.sa

How to cite this article: Sulimany AM, BinSaleh SS, AlYahya E, et al. Effect of Aging on the Microhardness of Different Resin-based Fluoride-releasing Fissure Sealants: An In Vitro Study. J Contemp Dent Pract 2021;22(10):1144-1149.

Source of support: Nil

Conflict of interest: None

the size of the fillers can affect the fracture resistance and are also shown to influence the viscosity of the sealants, ${ }^{16}$ which are critical for the infiltration of the material into occlusal pits and fissures. ${ }^{17}$ The wear resistance of filled and unfilled resin-based sealants is also affected by the degree of polymerization, which contributes to the ultimate long-term clinical performance of these matrix-based fissure sealants. ${ }^{15}$

There are many resin-based fissure sealants developed and introduced into the consumer market to overcome technique sensitivity due to moisture contamination of the majority of sealants and improve wear resistance while increasing anticaries behavior by the addition of fluoride. At the same time, there has been an increasing number of experimental studies to assess the mechanical and anticaries properties of resin-based fissure sealants. ${ }^{11,18-20}$ 
However, differences in polymerization at different time intervals between bioactive fluoride resin-based sealants and traditional non-fluoride-releasing fissure sealants have not yet been evaluated. There is also limited evidence for the effect of aging of various resin-based pit and fissure sealants. ${ }^{21}$

Therefore, this study aimed to compare the microhardness immediately and after the aging of three commercially available fluoride-releasing fissure sealants in vitro. These sealants have different chemical compositions (Table 1), namely Helioseal $\mathrm{F}^{\mathrm{TM}}$ (HF: Ivoclar Vivadent, Liechtenstein), Fissurit $\mathrm{F}^{\mathrm{TM}}$ (FF: VOCO, Germany), and the relatively newer sealant Embrace ${ }^{\mathrm{TM}}$ WetBond $^{\mathrm{TM}}$ (EWB: Pulpdent, USA). A non-fluoride-containing sealant (Eco-S: Vericom $\mathrm{Co}$, Korea) was used as a control. The null hypothesis was there is no detectable difference in the microhardness of the fissure sealant materials before and after aging.

\section{Materials and Methods}

\section{Sample Collection and Ethical Approval}

Forty-eight sound molar teeth were used in this study. The teeth were caries-free and were obtained from healthy adult patients aged 18-45 years with the patients' informed consent under a protocol reviewed and approved by the Institutional Review Board (IRB) at King Saud University (Riyadh, Saudi Arabia) and the College of Dentistry Research Center (CDRC) of King Saud University (Riyadh, Saudi Arabia). These patients were referred to the Oral and Maxillofacial Clinic of the Dental University Hospital at King Saud University to extract one or more teeth as part of their regular dental management. All teeth were stored in distilled water at $37^{\circ} \mathrm{C}$ and used within a week of extraction. Any teeth with caries lesions or enamel defects were excluded from the study.

\section{Study Design}

The four tested sealant materials were assigned to four different groups: Group A was allocated for Eco-S sealant (Vericom Co, Korea), a resin-based non-fluoride-releasing fissure sealant and designated as the control. Groups B, C, and D were designated as the resin-based fluoride-releasing fissure sealants, Helioseal $\mathrm{F}$ (Ivoclar Vivadent AG, Liechtenstein), Fissurit F (VOCO GmbH, Germany), and Embrace $^{\mathrm{TM}}$ WetBond (PULPDENT Corporation, USA), respectively. Details of the composition of each sealant material are described in Table 1. Each of the four groups was further divided into immediate and aging subgroups (Fig. 1).

\section{Specimen Preparation}

For each of the four groups, 12 extracted sound molar teeth were assigned. Each tooth was sectioned mesiodistally into two halves using a slow-speed water-cooled diamond blade (MetLab Technologies, Limited, London, UK). One half was assigned to the immediate subgroup, and the other half was assigned to the aged subgroup. A total of 12 sections were used in each subgroup for each sealant material (Fig. 1). A class V rectangular slot of $3 \times 2 \times 1 \mathrm{~mm}$ dimension in each tooth section was prepared on the buccal or lingual surface. Slots were acid-etched with $35 \%$ phosphoric acid for 15 seconds and then rinsed with water. The samples were gently airdried to remove excess water without over drying the exposed enamel within the slots. Each sealant material was then placed according to its manufacturer's instructions. The curing of the sealant materials was

Table 1: Summary of dental fissure sealants available commercially tested in this study

\begin{tabular}{|c|c|c|}
\hline Brand name & Manufacturer & Composition \\
\hline Helioseal F & Ivoclar Vivadent, Schaan, Lichtenstein & $\begin{array}{l}\text { Matrix: Bis-GMA, UDMA, TEGDMA } \\
\text { Filler: } 20 \% \text { wt. fluorosilicate glass, } 21.5 \% \text { wt. silicon dioxide } \\
\text { Fluoride: Yes }\end{array}$ \\
\hline Fissurit F & Voco, Cuxhaven, Germany & $\begin{array}{l}\text { Matrix: Bis-GMA, hexandioldimethacrylate, 7,7,9-trimethyl-4,13- } \\
\text { dioxo-3,14dioxa-5,12-diazahexandecan-1,16-diyldimethacrylate } \\
\text { Filler: 9.5\% wt. silicon dioxide } \\
\text { Fluoride: Yes }\end{array}$ \\
\hline Embrace WetBond & $\begin{array}{l}\text { Pulpdent Corporation, Watertown, } \\
\text { Massachusetts, USA }\end{array}$ & $\begin{array}{l}\text { Matrix: Urethane dimethacrylate (UDMA) } \\
\text { Filler: } 43 \% \text { wt. mixture of hydrophilic and hydrophobic materials } \\
\text { Fluoride: Yes }\end{array}$ \\
\hline Eco-S & Vericom Co., Ltd., Korea & $\begin{array}{l}\text { Matrix: Bisphenol A glycidyl dimethacrylate (Bis-GMA), triethy- } \\
\text { leneglycol dimethacrylate } \\
\text { Filler: Fumed silica } \\
\text { Fluoride: No }\end{array}$ \\
\hline
\end{tabular}

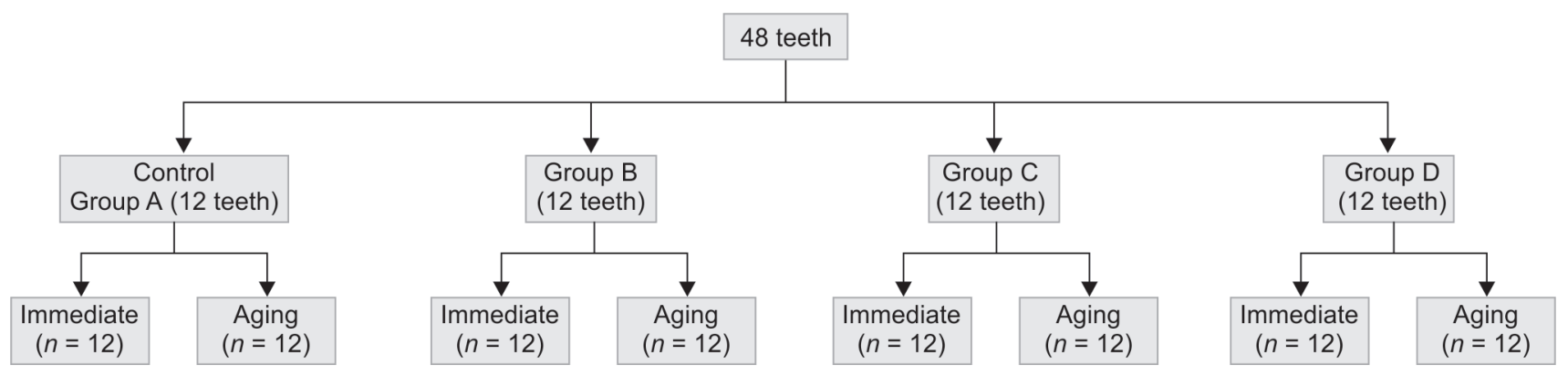

Fig. 1: Distribution of samples between the groups 
activated using the Elipar ${ }^{\mathrm{TM}}$ S10 LED curing light (3M ESPE, St. Paul, Minnesota, USA) (1200 mW/cm ${ }^{2}$ intensity) with a wavelength of 430 and $480 \mathrm{~nm}$ for 40 seconds. All sections were stored for 24 hours in distilled water at $37^{\circ} \mathrm{C}$. The first half was tested immediately from each tooth, and the other half were tested after aging.

\section{Thermocycling}

The samples assigned for the aging subgroup were subjected to the aging process using a thermocycling machine (SD Mechatronik Thermocycler, USA). The thermocycling was run for 1,500 cycles in water baths set at 5 and $55^{\circ} \mathrm{C}$ for 15 seconds at each temperature and 10 seconds dwell time between the two baths.

\section{Microhardness}

Vickers hardness test was used to measure the microhardness of the different sealant materials immediately and after aging. A microhardness tester (Micromet 2103, Buehler, Lake Bluff, Illinois, USA) with pyramidal diamond indenter at $50 \mathrm{~g}$ load was used to detect the Vickers hardness of the sealant surface. Each sample was measured at three different surface points located at the middle and the end of the sealant material with at least a $500 \mu \mathrm{m}$ distance between each point (Fig. 2). The Vickers hardness number (VHN) $\left(\mathrm{kg} / \mathrm{mm}^{2}\right)$ was recorded for each point.

\section{Statistical Analysis}

The effect of aging on the microhardness of different sealant materials was analyzed using a two-way analysis of variance

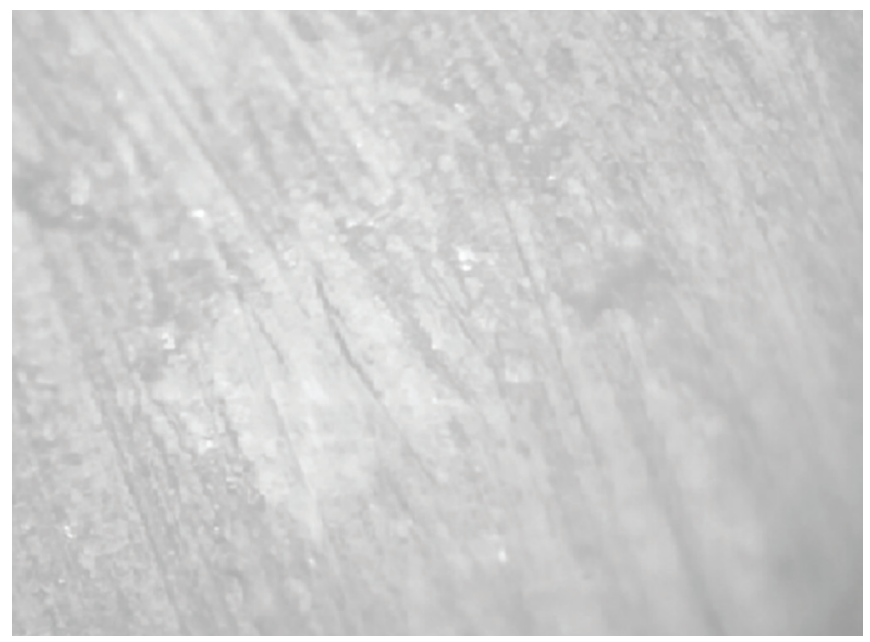

Fig. 2: The pyramidal diamond indentation on Eco-S sealant material
(ANOVA). Additionally, a one-way ANOVA was used to detect the difference between each sealant material at each time point. An independent $t$-test was used to determine the effect of aging for each sealant material. The level of significance was set at less than 0.05 ( $p$-value). All statistical analyses were performed using SPSS statistical software for windows (version 23; SPSS Inc., Chicago, Illinois, USA).

\section{Results}

The one-way ANOVA results for the immediate and aging groups for each material are presented in Table 2. The immediate VHN was the highest in the Helioseal F group $(27.62 \pm 5.83)$ followed by Eco-S $(27.33 \pm 2.31)$, Fissurit F $(25.91 \pm 3.55)$, and Embrace WetBond $(24.33 \pm 5.60)$. On the contrary, the VHN after aging was the highest in the Embrace WetBond group $(31.70 \pm 3.59)$, followed by Helioseal $F(29.75 \pm 3.30)$, Fissurit $F(28.43 \pm 5.21)$, and Eco-S (28.21 \pm 5.62$)$. However, there was no statistically significant difference in the VHN between sealant materials at both times.

Two-way ANOVA revealed no statistically significant difference in the mean VHN among the material groups $(p=0.72)$. On the contrary, there was a significant association between mean VHN and time factor $(p=0.001)$. Aging appeared to significantly increase the mean VHN. However, the interaction model showed that the effect of aging differs by the material type, where it was highly noticeable in the Embrace WetBond group (Fig. 3).

An independent $t$-test was performed for each material between the immediate and aging groups (Table 3). There was an increase in the mean $\mathrm{VHN}$ with aging across all the groups. However, the only statistically significant difference was found in the Embrace WetBond group, where the immediate VHN was $24.33 \pm 5.60$ and the aged VHN was $31.70 \pm 3.59$ at $p=0.001$.

\section{Discussion}

There is limited evidence on the effect of aging on the extent of curing represented by Vickers microhardness among different types of the fluoride-releasing pit and fissure sealants. ${ }^{21}$ Therefore, the purpose of the present study was to evaluate microhardness at different time intervals for comparative analysis of various fluoride-releasing resin-based sealants and a non-fluoride resinbased sealant.

Microhardness is considered an indirect measure of the degree of conversion (DC). DC is the magnitude of a polymer formed by the conversion of the monomer after irradiation. ${ }^{22,23}$ The most upper and lower layers of a sealant placed on the occlusal tooth surface are critical. ${ }^{22}$ Any low DC in those layers may result in deficiency in

Table 2: Association between VHN and material type

\begin{tabular}{llllc}
\hline Time & \multicolumn{1}{c}{ Material } & $N$ & $\begin{array}{l}\text { Mean }(\text { VHN }) \pm \text { Std. } \\
\text { deviation }\end{array}$ & $\begin{array}{c}\text { ANOVA } \\
\text { p value }\end{array}$ \\
\hline Immediate & Eco-S & 12 & $27.33 \pm 2.31$ & 0.28 \\
& Helioseal F & 12 & $27.62 \pm 5.83$ & \\
& Fissurit F & 12 & $25.91 \pm 3.55$ & \\
Aging & Embrace WetBond & 12 & $24.33 \pm 5.60$ & \\
& Eco-S & 12 & $28.21 \pm 5.62$ & 0.22 \\
& Helioseal F & 12 & $29.75 \pm 3.30$ & \\
& Fissurit F & 12 & $28.43 \pm 5.21$ & \\
& Embrace WetBond & 12 & $31.70 \pm 3.59$ & \\
\hline
\end{tabular}


Effect of Aging on Microhardness of Sealants

Table 3: Association between VHN and time factor

\begin{tabular}{llccc}
\hline Material & Time & $N$ & Mean $($ VHN $) \pm$ Std. deviation & $p$ value \\
\hline Eco-S & Immediate & 12 & $27.33 \pm 2.31$ & 0.62 \\
Helioseal F & Aging & 12 & $28.21 \pm 5.62$ & \\
& Immediate & 12 & $27.62 \pm 5.83$ & 0.28 \\
Fissurit F & Aging & 12 & $29.75 \pm 3.30$ & \\
& Immediate & 12 & $25.91 \pm 3.55$ & 0.19 \\
Embrace WetBond & Aging & 12 & $28.43 \pm 5.21$ & \\
& Immediate & 12 & $24.33 \pm 5.60$ & 0.001 \\
& Aging & 12 & $31.70 \pm 3.59$ & \\
\hline
\end{tabular}

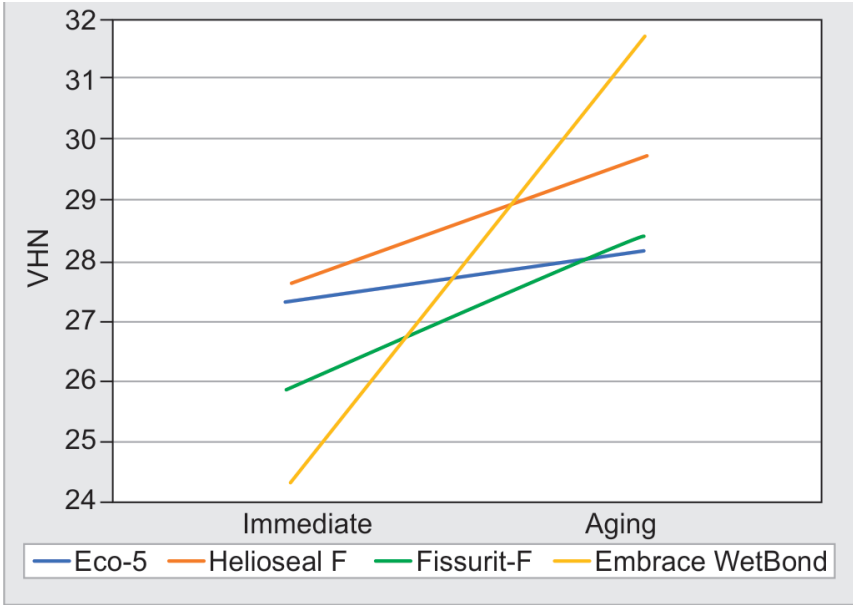

Fig. 3: The effect of aging on VHN stratified by the sealant material

marginal integrity, which will increase solubility, in turn permitting the proliferation of cariogenic bacteria with ultimate clinical failure of the sealant. 22,24

Although a difference in microhardness between fluoridereleasing sealants and the control group was anticipated, the results attained reflected otherwise. This could be due to the use of Eco-S as a control group, compared to previous studies that used Delton clear and Helioseal clear as a non-fluoride resin-based releasing sealant. ${ }^{25}$ Both of these materials have shown a lower mean of VHN compared to the VHN score of the Eco-S group in our study.

Although the Fissurit F sealant did not reach the highest VHN compared to other sealants, our score is higher than the Mazaheri et al. study, where they found a mean microhardness of $15.96 \pm 4.27$ for Fissurit $\mathrm{F}$ fluoride-releasing sealant. ${ }^{26}$ The reason for this lower value compared to our study findings could be due to their smaller sample size (nine samples). Other possibilities include differences in methodological design and outcome assessment tools.

Another study was published in 2019 to test the microhardness of Embrace WetBond and Helioseal F. The study showed a mean of 33 for WetBond and 26 for Helioseal F. ${ }^{27}$ Luckily, Helioseal F has a very close mean VHN score to what we can find in the literature. On the contrary, for Embrace WetBond, there was a large difference between the literature means and the mean value reported in this study, where the result mean was much lower. With this in mind, the difference could be attributed to the immediate testing of the sample in Diener et al. study. ${ }^{27}$

In this study, all the materials went through the aging process using a thermocycling machine for 1,500 cycles with a dual time of
10 seconds. It had revealed no significant difference between the samples in the immediate group and the aged group except for the Embrace WetBond group. There was a significant difference between the immediate and aged sample means in the latter group, with the microhardness increased with time. This could be explained by the Embrace WetBond sealant material's chemical composition, which is different from other sealants. The material contains high filler content with the urethane dimethacrylate (UDMA) matrix (Table 1). All other sealants have minimal fillers with the Bis-GMA matrix. Both functional monomers have a high affinity toward water during the initial setting, resulting in water sorption. ${ }^{28}$ However, Bis-GMA showed higher hydrophilicity due to the presence of hydroxyl functional group when compared to the urethane group. ${ }^{29}$ The absorbed water is presented either as unbound water that fills the nanopores between the polymer chains or as bound water that is attached to polymer chains by van der Waals forces or hydrogen bonds. Hydrolytic degradation occurs at the interface between the filler particles and the matrix polymer during the aging process. The presence of high filler content resulted in the reduction of such degradation and improved the material hardness. ${ }^{30}$ This could explain the increase in the VHN for the Embrace WetBond group.

Several experimental and clinical studies have compared some of the mechanical properties of Embrace WetBond to other fissure sealants and have shown superior physical characteristics in addition to its lesser sensitivity to moisture, ${ }^{31,32}$ while other studies have shown similar clinical success rates. ${ }^{33}$ In a recent clinical study, Embrace WetBond was found to exhibit lower wear and tear with greater marginal integrity (83\%), retention (97\%), and superior marginal adaptation (93\%) compared to other resinbased sealants. ${ }^{31}$ In another clinical study comparing Embrace WetBond to Helioseal F sealant, there was no difference between the two sealants in terms of retention, marginal adaptation, or caries development. ${ }^{33}$

An in vitro study by Zinelis et al. aimed to assess the microhardness at two different time intervals (at set and following 48 hours) of Embrace WetBond and Helioseal F. It was concluded that a statistical difference could be identified in terms of time, but no significant difference in terms of comparison of mechanical properties between the materials. ${ }^{27}$ It appears that there was a significant impact of the aging variable in the literature for Embrace WetBond material, and this result coincides with what we found in our study. Nonetheless, Helioseal F showed a significant difference between the set and the aged group, which contradicts our results. The difference in results could be explained by the small sample size used by Zinelis et al., which was only six samples, and the difference in the aging process, load, and dwell time for 
the Vickers hardness test. ${ }^{27}$ On the contrary, Thunyakitpisal et al. found no significant difference in the mean of microhardness of Helioseal $\mathrm{F}^{25}$ The study used 10 samples kept at room temperature for 24 hours before evaluating their microhardness. Their conclusion is comparable with the results found in our study for Helioseal F sealant material. Furthermore, an in vitro study by Kim et al., using a 10-g load indenter, found that Vickers hardness for Fissurit F sealant was reduced significantly after storage. ${ }^{34}$ This contradiction could be related to storing the samples in a dry container for a long time and the difference of the load chosen $(10 \mathrm{~g})$ for the Vickers hardness test.

A limitation of this study is that the sealant material was tested after it was applied on a smooth surface. This was to reduce the variations between samples. In the clinical situation, the sealants are applied in different types of fissures that have varying depths. This might affect the DC for the sealant materials and might behave differently than the current study results. The other limitation of the current research is that only resin-based sealant materials were used. It could be valuable to test the effect of aging on the microhardness of other sealant materials, such as glass ionomerbased sealant or flowable resin composite.

\section{Conclusion}

While there were no significant differences in the microhardness of commonly used fluoride-releasing fissure sealants, time appears to significantly increase the mean microhardness score (VHN), especially in the Embrace ${ }^{\mathrm{TM}}$ group. However, due to the presence of many variances that may contribute to the results in real clinical situations, such as the masticatory force, thermal variation, and intraoral chemical environments that may affect the specific materials, further in vivo studies are now needed.

\section{ACKNOWLEDgmentS}

The authors would like to thank Dr Nasr Muflahi from the College of Dentistry, King Saud University, for statistical support in this project. Also, they would like to express their gratitude toward the College of Dentistry Research Center as well as the Deanship of Scientific Research at King Saud University, Saudi Arabia, for their support in conducting this research.

\section{References}

1. James $\mathrm{SL}$, Abate $\mathrm{D}$, Abate $\mathrm{KH}$, et al. Global, regional, and national incidence, prevalence, and years lived with disability for 354 diseases and injuries for 195 countries and territories, 1990-2017: a systematic analysis for the Global Burden of Disease Study 2017. Lancet 2018;392(10159):1789-1858. DOI: 10.1016/S0140-6736(18)32279-7.

2. BaniHani A, Deery C, Toumba J, et al. The impact of dental caries and its treatment by conventional or biological approaches on the oral health-related quality of life of children and carers. Int J Paediatr Dent 2018;28(2):266-276. DOI: 10.1111/ipd.12350.

3. Souza JGS, Souza SE, Noronha MDS, et al. Impact of untreated dental caries on the daily activities of children. J Public Health Dent 2018;78(3):197-202. DOI: 10.1111/jphd.12259.

4. Carvalho JC. Caries process on occlusal surfaces: evolving evidence and understanding. Caries Res 2014;48(4):339-346. DOI: 10.1159/000356307.

5. Mejàre I, Axelsson S, Dahlën Ga, et al. Caries risk assessment. A systematic review. Acta Odontol Scand 2014;72(2):81-91. DOI: 10.3109/00016357.2013.822548.

6. Naaman R, El-Housseiny AA, Alamoudi N. The use of pit and fissure sealants - a literature review. Dent J (Basel) 2017;5(4):34. DOI: 10.3390/ dj5040034.
7. Horowitz $\mathrm{H}$, Heifetz $\mathrm{S}$, Poulsen S. Retention and effectiveness of a single application of an adhesive sealant in preventing occlusal caries: final report after five years of a study in Kalispell, Montana. J Am Dent Assoc 1977;95(6):1133-1139. DOI: 10.14219/jada.archive.1977.0201.

8. Lam PP, Sardana D, Lo EC, et al. Fissure sealant in a nutshell. Evidencebased meta-evaluation of sealants' effectiveness in caries prevention and arrest. J Evid Based Dent Pract 2021;21(3):101587. DOI: 10.1016/j. jebdp.2021.101587.

9. Charbeneau GT, Dennison JB, Ryge G. A filled pit and fissure sealant: 18-month results. J Am Dent Assoc 1977;95(2):299-306. DOI: 10.14219/ jada.archive.1977.0476.

10. Lam PP, Sardana D, Ekambaram M, et al. Effectiveness of pit and fissure sealants for preventing and arresting occlusal caries in primary molars: a systematic review and meta-analysis. J Evid Based Dent Pract 2020;20(2):101404. DOI: 10.1016/j.jebdp.2020.101404.

11. Alsabek L, Al-Nerabieah Z, Bshara N, et al. Retention and remineralization effect of moisture tolerant resin-based sealant and glass ionomer sealant on non-cavitated pit and fissure caries: randomized controlled clinical trial. J Dent 2019;86:69-74. DOI: 10.1016/j.jdent.2019.05.027.

12. Hatirli Hs, Yasa B, Yasa E. Microleakage and penetration depth of different fissure sealant materials after cyclic thermo-mechanic and brushing simulation. Dent Mater J 2018;37(1):15-23. DOI: 10.4012/ dmj.2016-234.

13. Kühnisch J, Bedir A, Lo Y-F, et al. Meta-analysis of the longevity of commonly used pit and fissure sealant materials. Dent Mater 2020;36(5):e158-e168. DOI: 10.1016/j.dental.2020.02.001.

14. O'Neill D, Nayyar J, Kinirons M, et al. Pit and fissure sealants-an update. J Irish Dent Assoc 2021;67(2):93-97. Available from: https://www. dentist.ie/journal/journal.5621.html

15. Faria $M$, Guedes $A$, Rompante $P$, et al. Wear pathways of tooth occlusal fissure sealants: an integrative review. Biotribology 2021;27:100190. DOI: 10.1016/j.biotri.2021.100190.

16. Prabhakar A, Murthy SA, Sugandhan S. Comparative evaluation of the length of resin tags, viscosity and microleakage of pit and fissure sealants - an in vitro scanning electron microscope study. Contemp Clin Dent 2011;2(4):324. DOI: 10.4103/0976-237X.91797.

17. Beslot-Neveu A, Courson F, Ruse ND. Physico-chemical approach to pit and fissure sealant infiltration and spreading mechanisms. Pediatr Dent 2012;34(3):57E-61E. Available from: https://aapd.publisher. ingentaconnect.com/contentone/aapd/pd/2012/00000034/00000003/ art00012

18. Şişmanoğlu S. Fluoride release of giomer and resin based fissure sealants. Odovtos 2019;21(2):45. DOI: 10.15517/IJDS.V0I0.36860.

19. Arora T, Arora D, Tripathi A, et al. An in-vitro evaluation of resin infiltration system and conventional pit and fissure sealant on enamel properties in white spot lesions. J Indian Soc Pedod Prev Dent 2019;37(2):133-139. DOI: 10.4103/1319-2442.261345.

20. Fernandes KS, Chalakkal P, De Ataide IDN, et al. A comparison between three different pit and fissure sealants with regard to marginal integrity. J Conserv Dent 2012;15(2):146. DOI: 10.4103/09720707.94588.

21. Hahnel S, Henrich A, Bürgers R, et al. Investigation of mechanical properties of modern dental composites after artificial aging for one year. Oper Dent 2010;35(4):412-419. DOI: 10.2341/09-337-L.

22. Borges $B C D$, Bezerra GVG, Mesquita JA, et al. Effect of irradiation times on the polymerization depth of contemporary fissure sealants with different opacities. Braz Oral Res 2011;25(2):135-142. Available from: https://www.scielo.br/j/bor/a/ymV8qmvD3qgdmCWkGrmfV5h/? format=pdf\&lang=en

23. Silikas N, Eliades G, Watts DC. Light intensity effects on resincomposite degree of conversion and shrinkage strain. Dent Mater 2000;16(4):292-296. DOI: 10.1016/s0109-5641(00)00020-8.

24. Kitchens B, Wells M, Tantbirojn D, et al. Depth of cure of sealants polymerized with high-power light emitting diode curing lights. Int J Paediatr Dent 2015;25(2):79-86. DOI: 10.1111/ipd.12102.

25. Thunyakitpisal P, Jiemsirilers $S$, Kashima D, et al. Depth of cure, flexural strength, microhardness, and cytotoxicity of light activated pit and fissure resin-based sealant experimental prototypes. CU Dent 
J 2016;39:43-52. Available from http://www.jdentinno.dent.chula. ac.th/upload/article/4/file_full_2215.pdf

26. Mazaheri R, Pishevar L, Keyhanifard N, et al. Comparing the effect of topical acidulated phosphate fluoride on micro-hardness of two fissure sealants and one flowable composite. Shahid Beheshti Univ Dent J 2014;32(2):103-110. DOI: 10.22037/jds.v32i2.24804.

27. Diener V, Zinelis S, Eliades T. Water-induced effects on the hardness and modulus of contemporary sealants derived from instrumented indentation testing (IIT). J Contemp Dent Pract 2019;20(6):653-656. Available from: https://www.thejcdp.com/doi/JCDP/pdf/10.5005/ jp-journals-10024-2574

28. Szczesio-Wlodarczyk A, Sokolowski J, Kleczewska J, et al. Ageing of dental composites based on methacrylate resins-a criticaleview of the causes and method of assessment. Polymers 2020;12(4):882. DOI: 10.3390/polym12040882.

29. Izabela M. Barszczewska-Rybarek. Characterization of urethanedimethacrylate derivatives as alternative monomers for the restorative composite matrix. Dent Mater 2014;30(12):1336-1344. DOI: 10.1016/j.dental.2014.09.008.
30. Aminoroaya A, Neisiany RE, Khorasani SN, et al. A review of dental composites: challenges, chemistry aspects, filler influences, and future insights. Compos Eng 2021:216. DOI: 10.1016/j. compositesb.2021.108852.

31. Baheti AS, Bhayya DP, Gupta $S$, et al. Assessment of clinical success of three sealants: Embrace-Wetbond, Clinpro, and Helioseal-F in permanent molars: an in vivo study. Pediatr Dent 2020;3(1):7-13. DOI: 10.5005/jp-journals-10077-3035.

32. Panigrahi A, Srilatha K, Panigrahi RG, et al. Microtensile bond strength of embrace wetbond hydrophilic sealant in different moisture contamination: an in-vitro study. J Clin Diagn Res 2015;9(7):ZC23. DOI: 10.7860/JCDR/2015/11662.6178.

33. Askarizadeh $\mathrm{N}$, Heshmat $\mathrm{H}$, Zangeneh $\mathrm{N}$. One-year clinical success of embrace hydrophilic and Helioseal-F hydrophobic sealants in permanent first molars: a clinical trial. J Dent (Tehran) 2017;14(2):92-99. Available from: https://www.ncbi.nlm.nih.gov/pmc/articles/PMC5662514/.

34. Kim J-W, Jang K-T, Lee S-H, et al. Effect of curing method and curing time on the microhardness and wear of pit and fissure sealants. Dent Mater 2002;18(2):120-127. DOI: 10.1016/s0109-5641(01)00030-6. 